\title{
Cost-Driven Design of a Large Scale X-Plane
}

\author{
Jason R. Welstead* \\ NASA Langley Research Center, Hampton, VA, 23681, United States of America \\ Peter C. Frederic ${ }^{\dagger}$ \\ Tecolote Research, Inc., Santa Barbara, CA, 93111, United States of America \\ Michael A. Frederick ${ }^{\ddagger}$ and Steven R. Jacobson ${ }^{\ddagger}$ \\ NASA Armstrong Flight Research Center, Edwards, CA, 93523, United States of America \\ Jeffrey J. Berton ${ }^{\S}$ \\ NASA Glenn Research Center, Cleveland, OH, 44135, United States of America
}

\begin{abstract}
A conceptual design process focused on the development of a low-cost, large scale Xplane was developed as part of an internal research and development effort. One of the concepts considered for this process was the double-bubble configuration recently developed as an advanced single-aisle class commercial transport similar in size to a Boeing 737-800 or Airbus A320. The study objective was to reduce the contractor cost from contract award to first test flight to less than $\$ 100$ million, and having the first flight within three years of contract award. Methods and strategies for reduced cost are discussed.
\end{abstract}

\section{Nomenclature}

$\begin{array}{ll}\mathrm{AR} & =\text { aspect ratio } \\ \mathrm{b} & =\text { span } \\ C_{L} & =\text { lift coefficient } \\ C_{t} & =\text { target contractor cost to first flight } \\ F & =\text { cost adjustment factor } \\ \mathrm{OEW} & =\text { operating empty weight } \\ \mathrm{S} & =\text { wing reference area } \\ \mathrm{t} / \mathrm{c} & =\text { thickness to chord ratio } \\ \mathrm{TOGW} & =\text { takeoff gross weight } \\ W_{e} & =\text { target empty weight } \\ \Lambda & =\text { wing quarter chord sweep }\end{array}$

\section{Introduction}

GINCE the 1990's, NASA has had few large scale, non-military manned experimental planes. With the Srelease of the 2017 proposed Presidential Budget, a new NASA vision for a series of large scale X-planes has been laid out called New Aviation Horizons, consisting of as many as five large scale subsonic transport demonstrators over the next decade. A challenge with any large scale demonstrator is the associated high

\footnotetext{
${ }^{*}$ Aerospace Engineer, ASAB, NASA Langley Research Center, 1 N Dryden St. M/S 442, Hampton, VA, 23681, Member AIAA.

$\dagger^{\dagger}$ Chief Scientist, Software Products and Services Group, Tecolote Research, Inc., 5266 Hollister Ave., Ste. 301, Santa Barbara, CA, 93111.

$\ddagger$ Aerospace Engineer, Research Engineering Directorate, Aerodynamics and Propulsion Branch, NASA Armstrong Flight Research Center, PO Box 273, MS 2228, Edwards, CA, 93523.

$\S$ Aerospace Engineer, Propulsion Systems Analysis Branch, M/S 5-11, NASA Glenn Research Center, Cleveland, OH, 44135, AIAA Senior Member.
} 
cost which, in the past, has proven prohibitive for the constrained NASA Aeronautics budget. Even with the New Aviation Horizons directive and supporting budget, containing cost to a reasonable level requires appropriate selection of research objectives, scale, and vehicle requirements.

In October 2014, an internal research and development (IRAD) effort started under the Convergent Aeronautics Solutions (CAS) project within the Transformative Aeronautics Concepts Program (TACP) to research solutions and approaches on how to design, build, and operate a low cost X-plane. The effort, originally called the Towed X-Plane study, initially had a charter to determine the feasibility of gaining high research value at low cost by towing the $\mathrm{X}$-plane, but was later expanded in scope to include towed and self-powered X-plane concepts and renamed the CAS X-plane project. The motivation of the study was not to select a specific concept to recommend as a future low-cost X-plane, but rather to employ innovative methods for cost reduction, identify unintended cost drivers typically associated with requirements, and explore alternative approaches for technology maturation with acceptable levels of risk. This study could then provide invaluable insight to the NASA Aeronautics Research Mission Directorate (ARMD) stakeholders to enable future X-plane request for proposal (RFP) that is shaped by the low-cost approach.

Ten advanced concepts were initially proposed for the study. To narrow the list of potential concepts for study, subject matter experts (SMEs) throughout NASA Aeronautics were consulted to rank the various concepts on the following criteria:

- Alignment with ARMD strategic thrusts ${ }^{1}$

- Degree of need for large scale flight test

- Commercial market entry potential

- Synergy with partners

- Technology readiness level (TRL) progression value

- Complexity and risk

- Concept heritage within NASA

- Vehicle class applicability

- Weight class as a surrogate for cost

- Suitability for towed test technique

- Concept appeal to public

Following the qualitative ranking by the SMEs, the list of ten potential concepts was narrowed to four: hybrid-wing-body, truss-braced-wing, double-bubble, and a modular testbed aircraft. A detailed description of the down select process is beyond the scope of this paper. Each concept was conceptually designed with both powered and unpowered configurations, with the scale of each configuration driven by concept specific selected research objectives and cost. The design process consisted of two iterations where a concept data package was populated and used in the cost estimation process employing a parametric cost estimation tool.

The focus of this paper is the conceptual design of a NASA D8 X-plane (ND8X) where the research objectives and cost were the design drivers. The ND8X is a scaled version of the NASA D8 (ND8), an in-house version of the D8 concept ${ }^{2-7}$ a double-bubble fuselage concept with top-mounted, rear fuselage boundary layer ingesting engines. Modeling tools for sizing, mission analysis, performance and cost estimates are described in Section II. A full description of the ND8X concept, starting with the development of a full-scale baseline, is discussed in Section III. Concluding remarks are found in Section IV.

\section{Modeling and Cost Estimation Approach}

\section{A. Geometry Modeling Using Open Vehicle Sketch Pad}

Open Vehicle Sketch Pad (OpenVSP) ${ }^{a}$ is a open source parametric geometry modeler used for a broad range of applications, but the software's strength lies in the conceptual modeling of aircraft components. ${ }^{8-16}$ In this study, OpenVSP was driven through an in-house custom JAVA plug-in for the Phoenix Integration ${ }^{\circledR}$ ModelCenter v11.2 software. Global design parameters such as wing area $(S)$, span $(b)$, quarter chord sweep $(\Lambda)$, thickness-to-chord ratio (t/c), and scale factor were provided to OpenVSP by the custom plug-in as design variables, and the geometry was automatically updated to reflect the changes. The updated geometry information was then fed back to ModelCenter from OpenVSP and used to drive the geometry inputs of the Flight Optimization System (FLOPS) ${ }^{17}$ sizing and synthesis software discussed in Section II-B.

${ }^{a}$ http://www.openvsp.org 


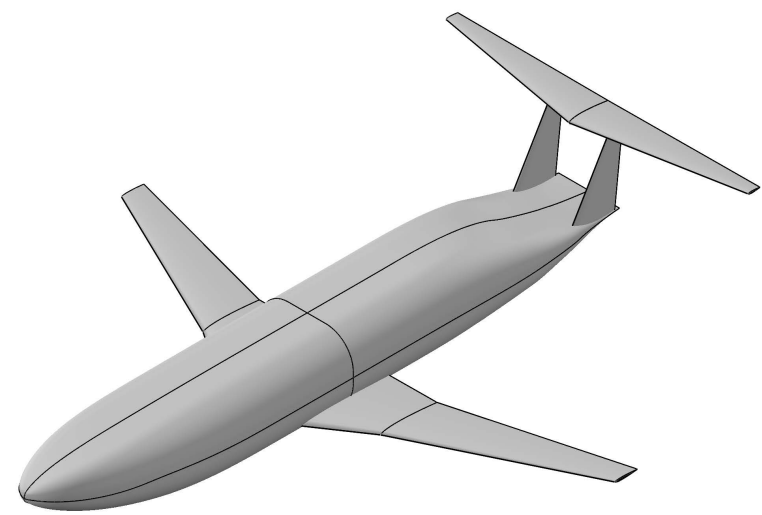

Figure 1. OpenVSP model of the ND8X.

A common challenge with any geometry is the translation from one geometry modeling software to another. A key feature of OpenVSP is the parameterization of the geometry components that allows for rapid updates to the geometry while maintaining an analytic definition of the surface geometry. The D8 double-bubble fuselage originally introduced by Massachusetts Institute of Technology (MIT) was a unique fuselage design that was modeled using tools that necessitated conversion of the geometry to a stereolithography (STL) file. The converted geometry can then be imported into OpenVSP.

A drawback of transferring geometry into OpenVSP via an STL was the loss of the geometry parameterization and so the geometry could not be freely modified in OpenVSP. Additionally, the source geometry was generated using 3D CAD and consisted of numerous parts, all of which did not translate smoothly into a watertight geometry in OpenVSP. This geometry issue was alleviated by a newer capability introduced in OpenVSP 3.x called Fit Model. Fit Model is a tool within OpenVSP that allows a user to fit a parameterized component to a cloud of points using a least squares fit and optimization. A watertight surface mesh was generated from a volume mesh used in computational assessments of a D8 1:11 scale model ${ }^{4}$ and converted to an STL file. This STL file was then used to generate a cloud of points and used in conjunction with the Fit Model tool to fit a parameterized fuselage component to the original geometry.

Figure 1 shows the ND8X concept, a scaled version of the ND8 concept, as modeled in OpenVSP. The imbedded engines were not modeled for simplicity.

\section{B. Sizing and Synthesis}

The system analysis of the ND8 X-plane concept was performed using an in-house developed tool called the Flight Optimization System (FLOPS). ${ }^{17}$ FLOPS is a monolithic FORTRAN code that was continuously developed from the mid-1980s until 2011, and has been a workhorse tool for a broad range of applications. The longevity of FLOPS is attributed to the extreme flexibility that was built into the tool. The user is allowed to highly customize the analysis through various k-factors and adjustments that modify the underlying methods with FLOPS enabling technology trades, sensitivity analysis, and analysis of alternatives. This flexibility made it a great tool for the analysis of the ND8 X-plane concept.

Four modules were used in the FLOPS analysis including aerodynamics, propulsion, weights, and performance. The propulsion module has the ability to internally generate a table of fuel flows and thrusts as a function of Mach number and altitude, also known as an engine deck, for various types of turbofans and turboprops. The propulsion module can also read in a table of thrust and fuel flows as a function of Mach number and altitude. The table is then used in the mission analysis routine where points are interpolated or extrapolated as necessary. The turbofan models for the ND8X were modeled using the Numerical Propulsion System Simulation (NPSS ${ }^{18-20}$ software generating an engine deck that was read directly into FLOPS.

The internal aerodynamics model within FLOPS is based upon the Empirical Drag Estimating Technique (EDET),${ }^{21,22}$ but the internally generated polars can be highly modified or overridden if aerodynamic improvement technologies are being modeled, or an external aerodynamic analysis has been performed through CFD. The aircraft component weights are estimated using in-house statistically derived empirical/semiempirical weight equations based upon geometry, mission requirements, gross weight, etc. In the case of a hybrid wing body concept, additional weight equations can be used for estimating the center-body structure based upon the work of Bradley. ${ }^{23} \mathrm{~A}$ more detailed description of the transport aircraft FLOPS equations, and the aircraft used to generate them, is given in Refs. 24 and 25.

The mission profile is modeled through a series of segments selected by the user including climb, cruise, descent, and hold. A general mission profile was used for the ND8 X-plane concept, but each concept's specific flight profile was driven by the concept specific research requirements. The nominal mission for the CAS X-plane study consisted of a thirty minute startup and taxi, a two minute takeoff, and a three hour flight profile including climb, cruise, and descent. A twenty minute hold time was included as a small reserve if required, and no missed approach was assumed. The taxi and shutdown time was estimated at fifteen minutes to complete the nominal mission profile. The mission profile is shown in Fig. 2. 


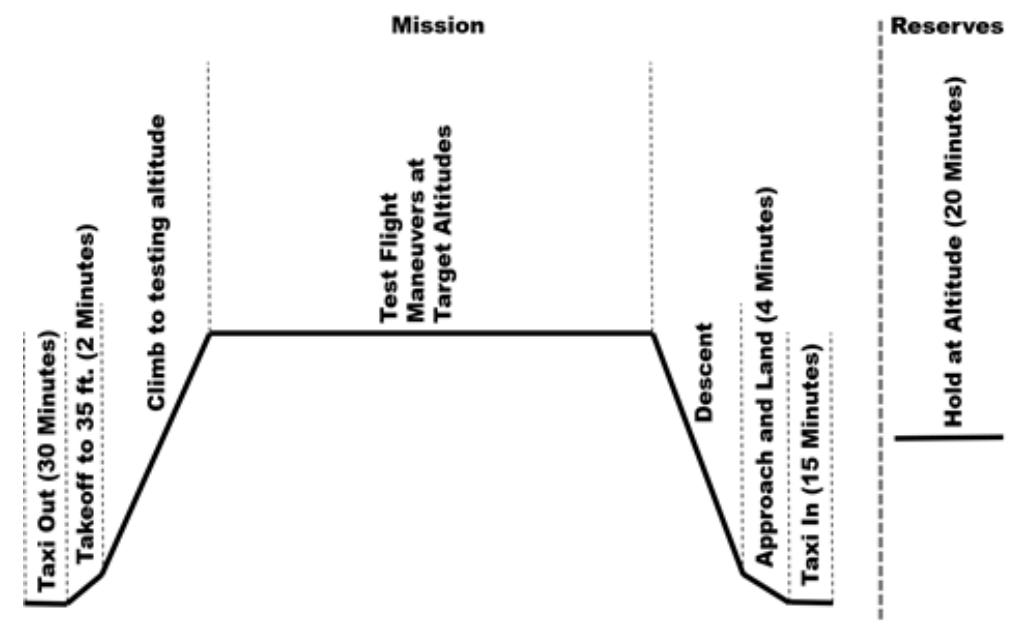

Figure 2. Standard mission profile used in the X-plane analysis.

Table 1. Summary of FLOPS input weight assumptions specific to an X-plane.

\begin{tabular}{|c|c|c|}
\hline Group Weight & Assumption & Comment \\
\hline Anti-icing & $0 \mathrm{lb}$ & X-plane will not fly through icing conditions \\
\hline Air conditioning & $500 \mathrm{lb}$ & $\begin{array}{l}\text { Piloted cockpit only, cooling for crew, avionics, and in- } \\
\text { strumentation }\end{array}$ \\
\hline Air conditioning & $130 \mathrm{lb}$ & Unpiloted (avionics/instrumentation need to be cooled) \\
\hline Instruments & $200 \mathrm{lb}$ & $\begin{array}{l}\text { Based upon } 33,000 \text { pound X-plane, scaled based upon X- } \\
\text { plane gross weight }\end{array}$ \\
\hline Avionics & $500 \mathrm{lb}$ & $\begin{array}{l}\text { Based upon } 33,000 \text { pound X-plane, scaled based upon X- } \\
\text { plane gross weight }\end{array}$ \\
\hline Furnishings & $256 \mathrm{lb}$ & $\begin{array}{l}\text { Includes the furnishings for crew, but not traditional fur- } \\
\text { nishings of a commercial transport aircraft }\end{array}$ \\
\hline Auxiliary power unit weight & $375 \mathrm{lb}$ & Weight per auxiliary power unit \\
\hline Crew & 2 & Two crew on board, a pilot and flight test engineer \\
\hline Cargo & $500 \mathrm{lb}$ & Test instrumentation $(\min =200, \max =500)$ \\
\hline
\end{tabular}

To ensure commonality in the modeling assumptions between the four X-plane concepts, a standard set of assumptions were made concerning some of the component weights of the vehicle. FLOPS was designed to model aircraft ranging from general aviation, regional and large commercial transports, to fighter aircraft. These types of aircraft contain all the subsystems for standard flight operations of a production vehicle, not a uniquely built X-plane that will not adhere to all operations and certification requirements. To account for this, some of the inputs for the subsystems and payload weights were modified or overridden based on flight testing experience of NASA Armstrong Flight Research Center team members. A summary of the weight assumptions are described in Table 1.

\section{Parametric Cost Estimation Tool}

A parametric cost model called the Probabilistic Technology Investment Ranking System (PTIRS) was used to estimate the development and production cost of the ND8X. PTIRS is a complete life cycle cost model for commercial aircraft development, production, and operations. The PTIRS development and production cost estimating relations (CERs) are calibrated to reproduce published prices for commercial transport aircraft, given reasonable assumptions regarding amortization of development costs, return on investment capital, and manufacturer's pricing mark-ups. PTIRS operations CERs are derived directly from actual airline operations data from the U.S. Department of Transportation's Bureau of Transportation Statistics 


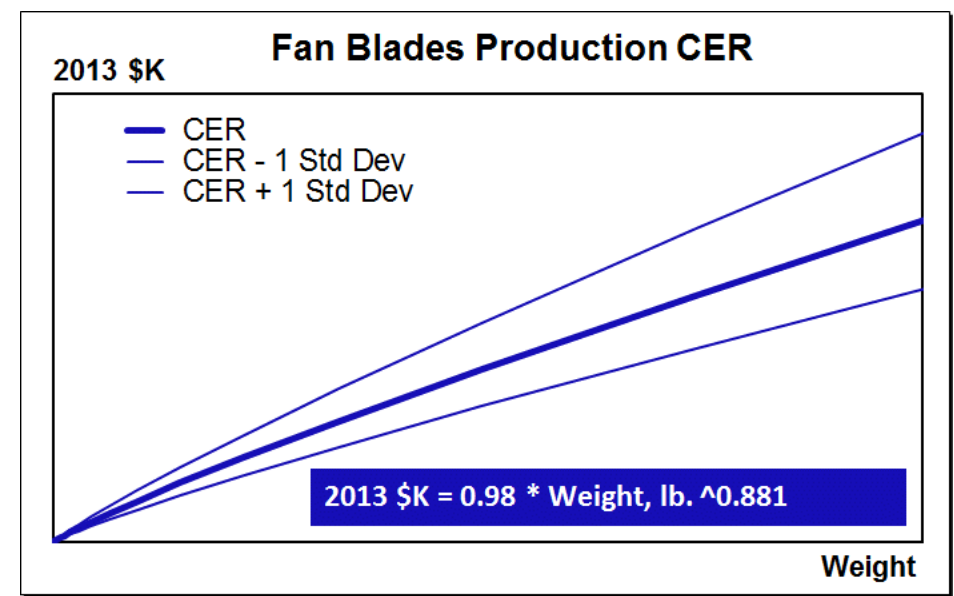

Figure 3. Sample PTIRS CER.

Form 41 database. The PTIRS CERs are all simple in form, and are all based on current technologies. For example, Fig. 3 represents the PTIRS CER for jet engine fan blade production. The CER in Fig. 3 estimates first engine fan blade set production costs based on weight. It is based on a database of 18 engines currently in production.

The PTIRS CERs include no subjective adjustment terms that magically address as yet undiscovered technologies. However, the PTIRS CERs differ from other widely-used aircraft cost models such as the RAND DAPCA-III model in that the PTIRS CERs estimate costs at the subsystem, and in some cases the assembly level, whereas DAPCA-III and others estimate costs at the total airframe level. The ability to break costs out to lower levels of detail enables the PTIRS tool to accurately reflect the implementation impacts of new technologies. For non-recurring costs, simple cost adjustment factors are applied directly to the PTIRS core CER results to reflect design re-use. For example, if a wing design from a prior aircraft is to be used with minor modifications, and the modifications are judged to be equivalent to $10 \%$ of the original design and tooling effort, then a new design factor of 0.1 will be applied to the CER results. Additional adjustment factors were developed and applied to reflect the unique requirements of flight demonstration projects:

- Design requirements for operability, reliability, maintainability, etc. were less stringent.

- Reduced, focused performance requirements and wider design margins allowed less detailed design analysis.

- High production rate tooling was not required.

- Less stringent production requirements for minimizing weight and wider design margins.

- "Rapid prototyping" fabrication methods with less stringent quality control were acceptable.

- Program management can be streamlined by reduction of reviews and government oversight.

- Engineering documentation requirements were reduced.

These factors were based on proprietary data provided by major airframe developers in the course of previous flight demonstration studies.

A custom data package was used to transfer the vehicle level inputs into the cost analysis. Required information for the data package included vehicle subsystem weights, fuel and payload weights, static thrust requirements, and a high level approximation of the use of composites. Salvaged subsystems were indicated in the data package along with an input for the new design factors, a parameter that captures the amount of design engineering required to integrate that subsystem into the vehicle. Any technologies a weight based cost estimating relation would not be able to capture, such as an active flow control system, was included in the data package. The programmatic cost were captured in the data package through the development of a program schedule and an estimate of required personnel resources. All the information in the data package was then fed to PTIRS for the cost analysis. 


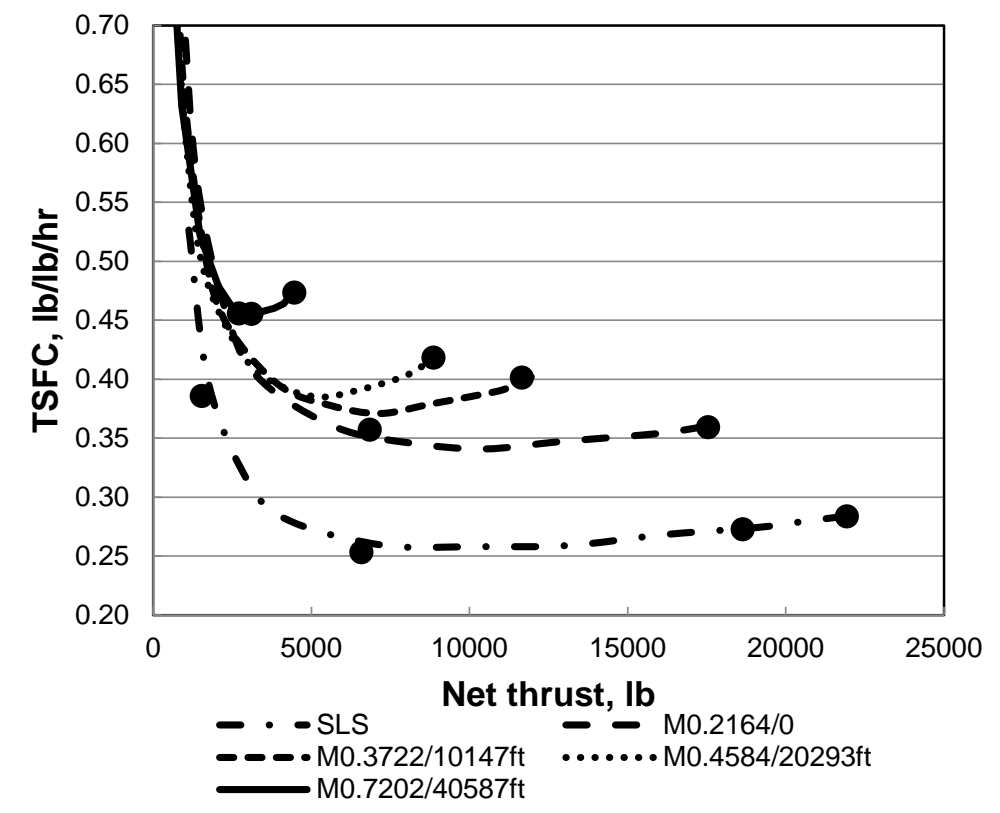

Figure 5. Surrogate engine model generated from TASOPT output of the D8.2 concept. ${ }^{3}$ The symbols were data taken from the D8.2 TASOPT output file, and the lines were generated from the surrogate model.

\section{Development of the ND8X}

By design, the CAS X-plane project had two iterations of the conceptual modeling and cost estimation. This was intended to provide an opportunity for design adjustments in Iteration 2 based upon Iteration 1 cost results to the research objectives, vehicle scale, use of commercial off-the-shelf (COTS) parts, composites, etc. The approach for the ND8X was to knowingly design a vehicle of excessively large scale for the first iteration, and through the cost analysis identify any major cost drivers to smartly design the Iteration 2 ND8X concept to hit the contractor cost to first flight metric of less than $\$ 100$ million.

To develop a conceptual model of the ND8X, first an in-house conceptual model of the objective vehicle (ND8) had to be developed that was not restricted to matching certain geometry inputs and assumptions from external resources, such as wing sweep and technology factors. This in-house version of the MIT D8 was called the NASA D8 (ND8), and was based upon the 2010 technology version of the concept called the D8.2. ${ }^{3}$ The Iteration 1 configuration was designed for a cruise speed of Mach 0.72. This allowed for a consistent set of modeling assumptions and tools between the full scale vehicle and the subscale X-plane concept. Modeling tools used in the development of the ND8 included FLOPS and OpenVSP integrated into Phoenix Integration's ModelCenter v11.2 engineering environment.

Several design assumptions were changed for the ND8 configuration from the original D8.2. The taper ratio was increased from 0.135 to 0.35 for improved tip-stall performance using recommendations from Raymer, ${ }^{26}$ the span was constrained to 118 feet which matches the current day B737/A320 aircraft and allows for Class C airport operations, and the ultimate load factor was increased to $3.75 \mathrm{~g}$ 's which is $1.5 \mathrm{x}$ the limit load for a commercial transport. This assumes there is no ultimate load reduction due to tech-

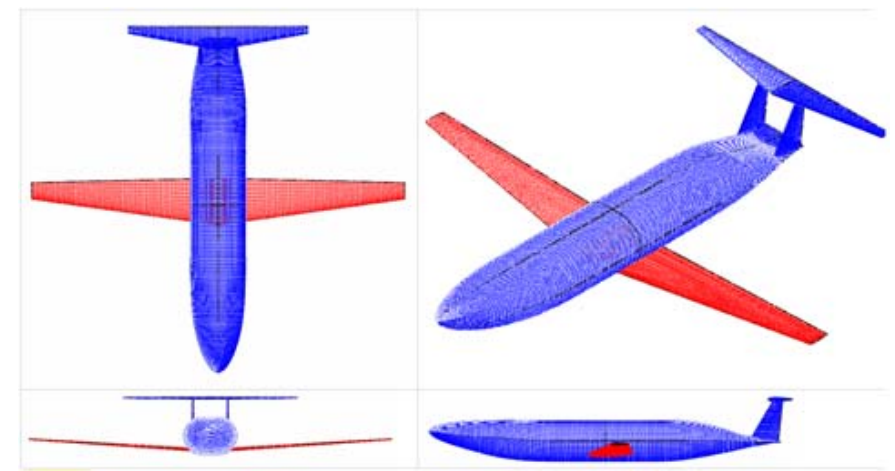

Figure 4. Conceptual model of the ND8 shown in OpenVSP. 
Table 2. ND8X proposed research objectives in the initial evaluation of the concept. *Items with priority 3 and 4 were removed from the final list of research objectives.

\begin{tabular}{lc}
\hline \hline Initially Proposed Research Objective & Priority Level \\
\hline Boundary layer ingestion propulsion system performance & 1 \\
Off-design boundary layer ingestion propulsion system oper- & 1 \\
ability & \\
Low-speed stability and control performance & 1 \\
Terminal area operations acoustic testing & 2 \\
Tool validation & 2 \\
Structural health monitoring system research & 2 \\
Structural validation of noncircular cross section with com- & $3^{*}$ \\
posite materials & $4^{*}$ \\
Natural laminar flow research & $4^{*}$ \\
High aspect ratio wing & $4^{*}$ \\
\hline Airport operations &
\end{tabular}

nologies such as structural health monitoring.

The horizontal and vertical stabilizer geometries were fixed to match the D8.2 and so were not resized with the wing, and a surrogate engine model was created to match the data from a Transport Aircraft Optimization (TASOPT) ${ }^{7}$ output file. The TASOPT output points can be seen in Fig. 5 along with curves of the surrogate model. Small discrepancies can be seen in the curves at low thrust values and lower Mach numbers, but the engine never enters this region during the standard mission and these discrepancies should have little to no impact on the quality of the surrogate model. The ND8 was then sized by varying the wing area and thrust to meet the full scale performance requirements of the D8.2 configuration, and this became the baseline ND8 configuration from which the ND8X was scaled, and is shown in Fig. 4.

The fundamental driver for the ND8 X-plane concept was to meet a clear set of research objectives in a cost effective manner where ground test alone would provide insufficient data to address key technical challenges. The research objectives and minimizing total cost were the drivers behind every decision in the conceptual development of the ND8X configuration. A careful balance had to be struck between the right research objectives and the associated cost implications. A cost saving measure that sacrificed a major research objective was considered unacceptable, and a research objective that was a major cost driver resulted in critical consideration of the research objective and its value to the program as a whole, and whether flight testing was critical to achieve that objective. A complete list of proposed research objectives for the ND8X is provided in Table 2 .

Natural laminar flow (NLF) was eliminated as a research objective following a discussion with natural laminar flow experts at NASA Langley Research Center. As originally proposed in the advanced D8 concept with entry into service in the 2035 timeframe, the underside of the wing was designed to have significant regions of natural laminar flow. However, due to operational considerations including accidental damage, disrupted surface continuity from access hatches and other maintenance requirements, and increased susceptibility of the lower wing surface to organic surface contaminants, sustained NLF on the lower wing surface without significant maintenance requirements was determined to be unrealistic. The emphasis for the ND8X also focused on the more current technology version (2010) of the ND8 which did not include NLF, and after consulting with the original concept developers at MIT it was determined that removing NLF had a minimal performance impact on the long term advanced concept. Considering all these items, NLF was removed as a research objective for the ND8X.

The double-bubble fuselage concept is not a new fuselage concept. The double-bubble layout is used in the Airbus A380, however the bubbles are stacked vertically which allows for the cabin floor between the upper and lower deck to be multifunctional as a structural floor and a pressure vessel tension strap. The double-bubble fuselage concept in the $\mathrm{D} 8$ concept is unique in that the twin fuselages are placed side-by-side and the floor can no longer be used as a structural tension strap (see Fig. 6). The hoop stresses must be carried by the noncircular cross section alone, or structurally supported by a tension strap that goes along 
the centerline of the fuselage through the passenger cabin. Designing the fuselage structure to handle loads experienced in flight along with the pressure load from the cabin pressurization at altitude is a challenging task. The use of state of the art composites and manufacturing practices, such as automated fiber placement, is envisioned to reduce the structural penalty associated with the noncircular cross section.

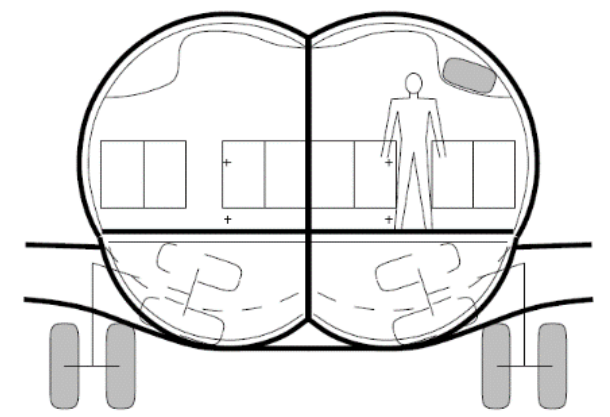

Figure 6. Cross-section view of the double-bubble fuselage of the D8concept. 6

sacrificed in light of previous discussion.

High aspect ratio wing technologies were not a fundamentally enabling technology for the ND8 concept in that enhancements to transonic wing design and structural efficiency for higher aspect ratios would apply equally to a conventional configuration as it would to the ND8. As such, a more conventional, span restricted wing was selected as a risk reduction measure and applied the full scale ND8, and then scaled to the ND8X.

\section{A. Iteration 1 ND8X Design}

An emphasis was placed on a large scale X-plane, and the selection of the vehicle scale is driven by multiple factors including the ability to integrate subsystems such as crew accommodations and propulsions systems, vehicle cost correlated to the vehicle empty weight, but most importantly the ability to successfully meet the research objectives. Based upon feedback from aircraft manufacturers, even with advanced composite materials and their potential weight reductions, a strong correlation still exists between vehicle cost and empty weight for a one-off vehicle like an X-plane. To successfully meet the boundary layer ingestion (BLI) propulsion system performance research objective, guidance from the testing experts of the Boundary Layer Ingesting Inlet Distortion Tolerant Fan (BLI $\left.{ }^{2} \mathrm{DTF}\right)$ wind tunnel test occurring at NASA Glenn Research Center in Fall 2016 emphasized that both Reynolds number and Mach number matching of the full scale vehicle was of utmost importance. Reducing vehicle scale reduces the total vehicle cost, but matching both Reynolds number and Mach becomes increasingly difficult. The ND8X vehicle scale was selected based upon matching the full scale Mach number, and reducing the testing altitude to match Reynolds number without reaching excessive levels of dynamic pressure.

The emphasis for the first iteration of the ND8X configuration was to select a large scale vehicle, mostly likely too large from a cost perspective, that gave a test flight condition under 25,000 feet, avoiding crew pressurization for the manned vehicle. As part of the CAS X-plane study, a comprehensive trade study was performed to understand the cost implications of an unmanned versus manned X-plane. ${ }^{27}$ From the results of this study, a manned vehicle was chosen as the lower cost option as autonomy was not part of the concept's research objectives.

Boundary layer ingestion research was the highest priority and a fundamental enabling technology for the ND8 concept as a potential future commercial transport. It was known that two design iterations would be performed and design changes could be made after the Iteration 1, so $70 \%$ scale was selected which gave a design flight condition of Mach 0.72 at 24,500 feet. With the $70 \%$ scale selected, a sensitivity of cost to concept scale and design could be established which would then drive the Iteration 2 design.

The ND8X was modeled using FLOPS and OpenVSP where the cruise segment of the mission was constrained to the target altitude at the design velocity of Mach 0.72, and the cruise length was varied to give a mission endurance of four hours. This was the target endurance that was selected for the Iteration 1 ND8X, but was later reduced to three hours in Iteration 2 (see Section III-B) to be consistent with the other 


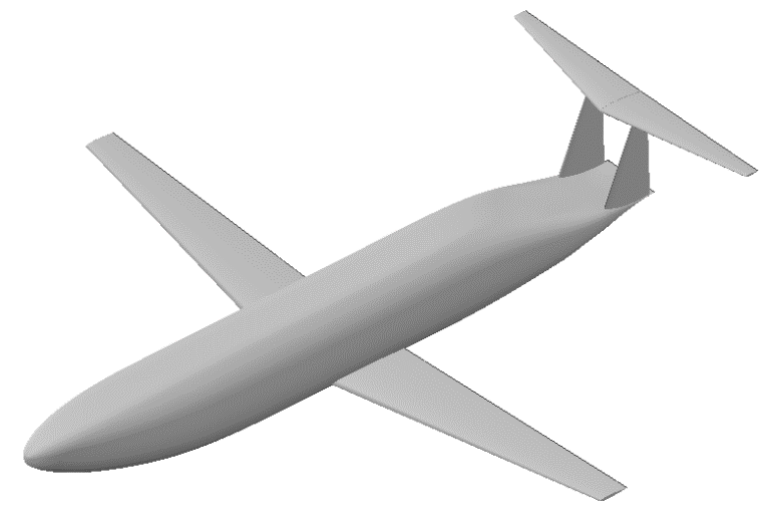

Figure 7. Conceptual geometry for the $70 \%$ scale ND8X modeled in OpenVSP.

Table 3. Summary of varied FLOPS inputs to feed the cost estimate.

\begin{tabular}{lccc}
\hline \hline Input & Minimum & Most Likely & Maximum \\
\hline Fuselage Structural Weight Factor & 0.9 & 1 & 1.1 \\
Maximum Mach Number & 0.77 & 0.77 & 0.82 \\
Instrumentation Payload & $200 \mathrm{lb}$ & $500 \mathrm{lb}$ & $500 \mathrm{lb}$ \\
Cargo Floor Reinforcement & No & No & Yes \\
Taxi Out Time & $20 \mathrm{~min}$ & $30 \mathrm{~min}$ & $45 \mathrm{~min}$ \\
Ultimate Load Factor & 2.5 & 3.75 & 4.5 \\
\hline
\end{tabular}

X-plane concepts being modeled as part of the CAS X-plane study. An isometric view of the scaled concept is shown in Fig. 7.

No specific engine was selected for the first iteration of the ND8X, so the surrogate engine model was scaled to the sea level static thrust required to successfully complete the mission. The surrogate model was a high bypass ratio turbofan, so scaling this engine model to this extreme means that the thrust lapse, cycle performance, and thrust specific fuel consumptions (TSFC) were not representative of a turbofan in the 6000 $\mathrm{lb}$ thrust class. Given that the design would be refined in Iteration 2, and that the additional fuel required due to the less efficient, smaller turbofans would have a minor impact on the total vehicle gross weight, this modeling error was determined to be acceptable at this point in the study.

For the cost estimate it was assumed that several subsystems would be used from donor aircraft or commercial off the shelf (COTS). The subsystems included landing gear, APU, instrumentation, hydraulics, the flight control subsystem, electrical subsystems, environmental control systems, and a COTS engine that was refanned to handle the inflow distortion. This makes the large assumption that an off-the-shelf engine can be refanned and safely perform in the BLI environment. New design engineering was required for the airframe, the inlet and nacelle, and half of the engine, with new design engineering required to integrate the donated systems and new airframe. All airframe structural components were assumed to be composite materials except the landing gear.

To complete the cost data package for the concept cost estimate, variations on the inputs were selected to provide the minimum, most-likely, and maximum values. Since most of the CERs have a weight based correlation, inputs were selected that have an impact on the vehicle structural weight, and therefore the vehicle gross weight. A summary of the varied FLOPS inputs for the cost estimate is provide in Table 3.

A summary of the ND8X design at the end of Iteration 1 is provided in Table 4. From the cost estimate, the ND8X had a total program cost of $\$ 446 \mathrm{M}$ at the $50 \%$ confidence level, and $\$ 506 \mathrm{M}$ at the $80 \%$ confidence level. This total program cost includes all government and contractor costs. The contractor cost to first flight, the key metric for the study, was $\$ 394 \mathrm{M}$ which well exceeds the target of $\$ 100 \mathrm{M}$. Reducing this total cost requires several design changes that were performed during Iteration 2. 


\section{B. Iteration 2 ND8X Design}

The Iteration 1 ND8X design was excessively costly as expected due to the large scale and significant large new design factors. It was desired to understand the key cost drivers of the vehicle in order to better select the scale of the vehicle. The research value of the vehicle drives the $\mathrm{X}$-plane sizing to larger scales, whereas minimizing cost typically drives the scale down resulting in a reduced vehicle empty weight, and therefore a reduced gross weight. A balance must be struck between these contradicting desires in order to have a vehicle of acceptable research value while remaining within a constrained budget. In addition to reducing the empty weight, identifying the parameters that adjust the slope of cost versus empty weight curve was highly desirable as adjusting these cost drivers allowed for significant reduction in cost with minor decreases in scale.

During the Iteration 1 cost analysis for the four $\mathrm{X}$-plane concepts used in the study it was determined that the key drivers for reducing the concept cost in-

Table 4. Summary of the nominal ND8X Iteration 1 design.

\begin{tabular}{lrl}
\hline \hline Summary of ND8X Iteration 1 & Nominal & Design \\
\hline Takeoff Gross Weight & 33,300 & $\mathrm{lb}$ \\
Vehicle Scale & $70 \%$ & - \\
Fuel Weight & 11,800 & $\mathrm{lb}$ \\
Endurance & 240 & $\mathrm{~min}$ \\
Wing Area & 580 & $\mathrm{sq} \mathrm{ft}$ \\
Aspect Ratio & 13.5 & - \\
Sweep & 5.6 & $\mathrm{deg}$ \\
Thrust (total, SLS) & 11400 & $\mathrm{lb}$ \\
Mach Number & 0.72 & - \\
Total Cost Estimate (50\%) & 446 & $\$ \mathrm{M}$ \\
Total Cost Estimate $(80 \%)$ & 506 & $\$ \mathrm{M}$ \\
Contractor Cost to First Flight & 394 & $\$ \mathrm{M}$ \\
\hline
\end{tabular}
cluded vehicle empty weight, new design factors, and the use of salvaged parts. Reducing the empty weight was directly related to the vehicle scale. No excess payload was being carried in the vehicle that would allow for a reduction in structural weight if removed. The new design factors were major drivers of the vehicle cost and any reductions would have measurable impact. Along with reducing the amount of clean sheet design, making significant use of salvaged parts would drive the cost down. It was hoped that a combination of all three would provide a significant reduction in cost.

A target empty weight was desired to drive the X-plane scale with a high level estimate of the contractor cost to first flight. An empirical estimate of this cost was derived by taking the Iteration 1 results with the fixed inputs and halving all of the input weights of the ND8X configuration. The resulting trend was

$$
W_{e}=\left(\frac{C_{t}}{231.1 \times F}\right)^{\frac{4}{3}}
$$

where $W_{e}$ is the target empty weight in pounds, $C_{t}$ is the target contractor cost to first flight, and $F$ is an adjustment factor to account for modified new design factors, use of a salvaged wing, and engineering and manufacturing cost reductions representative of a "low-cost fabricator." The value for this factor was set to 0.59 following guidance from the cost analyst.

The above equation was used to generate the plot in Fig. 8 that shows the empirical estimate of the $\mathrm{X}$-plane empty weight versus contractor cost to first flight. This regression was used to establish an empty weight target that would then drive the vehicle scale. To target a cost of $\$ 150$ million, the vehicle empty weight would have to be in the region of 11,000 pounds. During some initial sizing exploration it was determined that the 11,000 pounds empty weight was driving the scale smaller than desired, and so the target cost was increased to $\$ 175$ million. This gave an empty weight target for the X-plane design of 14,000 pounds. The goal for contractor cost to first flight was $\$ 100$ million which was significantly lower than the specified $\$ 175$ million used in the empty weight target. It was hypothesized that the extra $\$ 75$ million could be reduced though more aggressive assumptions contrary to the more conservative approach of Iteration 1. This was done through aggressively reduced ground test, relying on innovative manufacturing processes and techniques for cost and schedule reduction, and significant use of salvaged parts wherever possible.

A design decision that impacted the X-plane design was to increase the target Mach number from 0.72 to 0.8 , with a maximum Mach number of 0.85 . This increase in Mach resulted from the desire to have the concept perform at the same Mach number as the current single-aisle commercial fleet. Most advanced configurations currently being studied in the Advanced Air Transport Technologies (AATT) project have increased from approximately Mach 0.7 to around Mach 0.8. The fullscale vehicle was resized in FLOPS to give a new baseline model for scaling with key changes in the design mostly isolated to increased wing sweep 


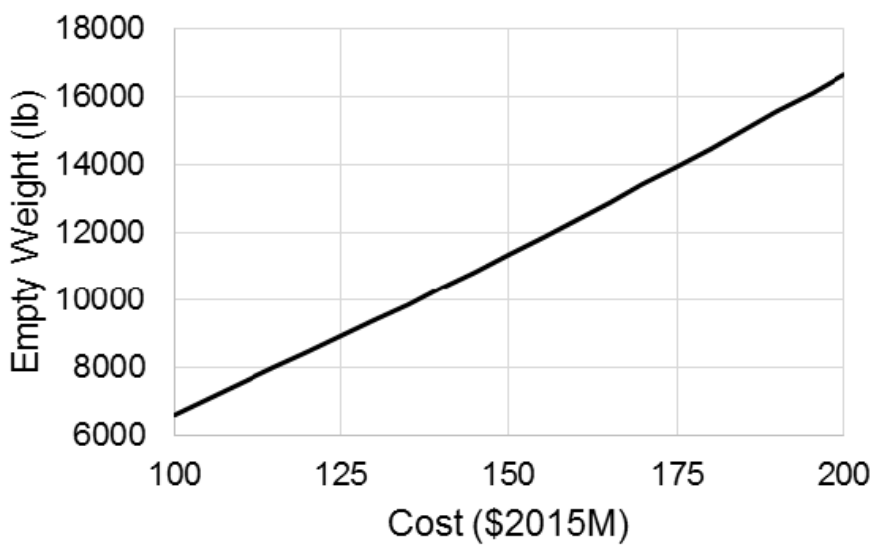

Figure 8. Empirical estimate of empty weight versus high level estimate of contractor cost to first flight.

and vehicle structural weight. The horizontal stabilizer and vertical stabilizers were kept fixed for simplicity, but will most likely have to be resized with increased sweep due to the higher Mach number and new wing sweep.

The regression of Fig. 8 assumed that a salvaged wing was been used for the X-plane. Because the ND8 concept does not depend on an advanced wing, and because wing development is particularly expensive in terms of dollars per pound, the wing was identified as the principal candidate for reuse of legacy hardware. A search of numerous general aviation aircraft was conducted to find a wing that was of relevant size (wing area and span), certified to a Mach number in excess of 0.8, was a low-wing configuration, and was on a vehicle certified to a higher MTOW than the proposed ND8X concept. The Gulfstream G150 was one of the few general aviation aircraft that met all the criteria, the most challenging criteria being the high transonic Mach number. The G150 wing span was approximately 50\% scale of the ND8 baseline wingspan, and a comparison of the baseline geometry at half scale (red wing) and the G150 wing (blue wing) is shown in Fig. 9. The wing weight was estimated using FLOPS to be 2,150 pounds using the G150 gross weight of 26,100 pounds. Since the salvaged wing structure would be fixed and could not be resized, the wing weight was fixed.

Boundary layer ingestion research was of highest priority (see Table 2) and was not directly dependent on the wing geometry. The ND8X at fifty percent scale was under the target empty weight discussed previously, so the fuselage and empennage scale to be decoupled from the wing. This allowed the fuselage and empennage to be sized at $60 \%$ scale with the fixed geometry G150 wing giving an empty weight near the target of 14,000 pounds.

An engine model of the CF34-8C5 was readily available and was much closer to the relevant engine thrust class, TSFC, and weight than the originally used D8.2 surrogate engine deck of Iteration 1. A sized ND8X required 5,080 pounds of thrust per engine which was very similar to a PW305B engine. The PW305B engine has half the thrust of a CF34-8C5 engine, but the cycle was more representative than the surrogate model. A specific engine model of the PW305B would improve the accuracy of the vehicle performance and

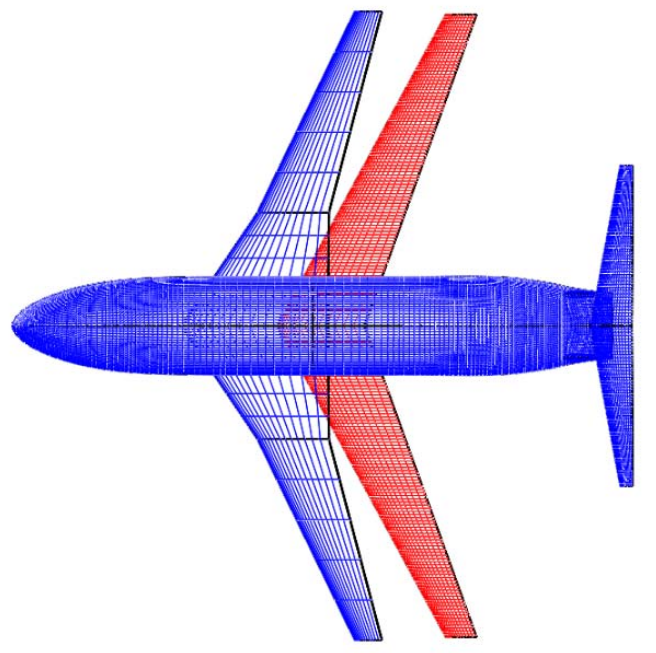

Figure 9. Baseline configuration at $50 \%$ scale showing the baseline wing (red) and the G150 wing (blue). G150 wing was moved forward for visual clarity. Note, empennage was unchanged from Iteration 1 for simplicity. 
fuel burn, but would have minimal impact on the final

result, especially since the TSFC of the scaled engine was adjusted to match the PW305B.

The ND8X mission profile was modified to include a 180 minute flight time which was reduced from 240 minutes in Iteration 1 for consistency across all the X-plane concepts. The reduced scale of the fuselage from Iteration 1 resulted in the target flight condition for cruise to be reduced to around 22,200 feet. The ND8X geometry is shown in Fig. 10 as modeled in OpenVSP. The rear engines are shown in red with nacelles sized to house a PW305B engine.

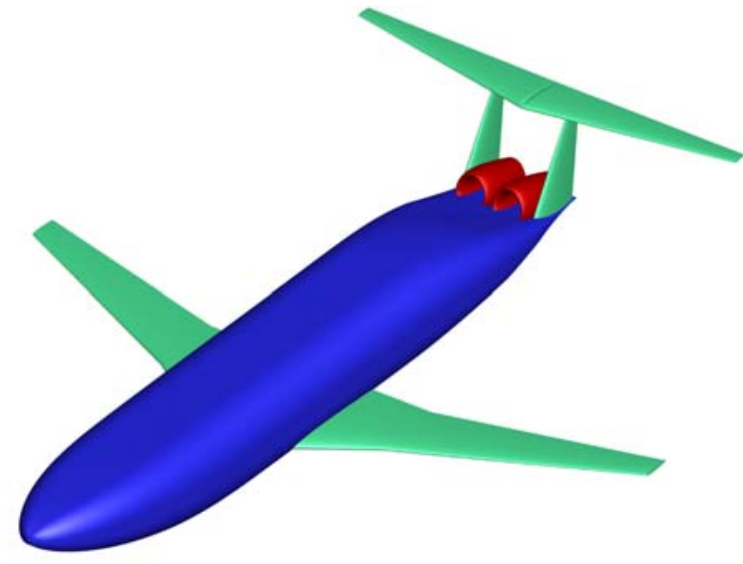

Figure 10. OpenVSP geometry of the twinengine ND8X configuration.

Similar to Iteration 1, variations in the inputs were used to feed the cost data package that would be used to generate the statistical cost estimate. The selected inputs were similar to Iteration 1 with an emphasis in selecting the inputs that would have a weight impact on the concept. Changes from Iteration 1 include the addition of the structural weight factor for the vertical stabilizers, the increase in maximum Mach number to reflect the increased design Mach number, and the elimination of the cargo floor option. The cargo floor reinforcement option was removed as a varied input due to the unnecessarily large impact on the structural weight. The ultimate load factor input range was also narrowed from the Iteration 1 inputs. A summary of the varied inputs to generate the outputs for the data package are summarized in Table 5.

Table 6 summarizes the structural weights for the minimum, most-likely, and maximum values resulting from the input variations described in Table 5. Worth noting is the most-likely design empty weight of 13,974 pounds which was right at the empty weight target established above. As before, the design made extensive use of composites in the structural elements of the fuselage, horizontal and vertical stabilizers, and the engine inlets and nacelles. The amount of composites in the wing were significantly reduced as the wing was salvaged from a G150.

New design factors were a major cost driver in the Iteration 1 design. To ensure the best possible estimate for the new design factor inputs in the cost estimation data package, extensive conversations were held with the cost analyst to come to an agreement on the selected inputs. Salvaged parts were used wherever possible including the wing, main and nose landing gear, engine, engine controls and fuel system, auxiliary power unit, flight instruments, hydraulics, electrical systems, furnishings, and environmental control systems. A survey of used G150s yielded an average purchase price of $\$ 8.5$ million for a complete G150, and this was included in the Iteration 2 cost estimate, along with allowances for the cost of dismantling the G150 and the engineering and manufacturing cost of integrating the wing into the ND8X. All these items were discussed and critically reviewed by the designer and the cost analyst at a conceptual level.

Although the rescaling of the vehicle and the adoption of the G-150 donor aircraft resulted in significant cost savings, this was tempered to some degree by making several of the new design factors more conservative. In Iteration 1, it was assumed that the salvaged subsystems, as well as the fuel and flight control subsystems

Table 5. Summary of varied FLOPS inputs to generate the outputs required for the Iteration 2 cost estimate data package.

\begin{tabular}{lccc}
\hline \hline Input & Minimum & Most Likely & Maximum \\
\hline Fuselage Structural Weight Factor & 0.9 & 1 & 1.1 \\
Vertical Tail Structural Weight Factor & 0.95 & 1 & 1.05 \\
Maximum Mach Number & 0.85 & 0.85 & 0.87 \\
Instrumentation Payload & $200 \mathrm{lb}$ & $500 \mathrm{lb}$ & $500 \mathrm{lb}$ \\
Taxi Out Time & $20 \mathrm{~min}$ & $30 \mathrm{~min}$ & $45 \mathrm{~min}$ \\
Ultimate Load Factor & 3.25 & 3.75 & 4.25 \\
\hline
\end{tabular}


Table 6. High level group weights for the Iteration 2 ND8X.

\begin{tabular}{llccc}
\hline \hline Subsystem & Units & Minimum & Most-likely & Maximum \\
\hline Fuselage & $\mathrm{lb}$ & 4462 & 4958 & 5454 \\
Wing & $\mathrm{lb}$ & 2151 & 2151 & 2151 \\
Empennage & $\mathrm{lb}$ & 543 & 570 & 595 \\
Landing Gear & $\mathrm{lb}$ & 745 & 774 & 795 \\
Propulsion & $\mathrm{lb}$ & 2423 & 2424 & 2427 \\
Subsystems & $\mathrm{lb}$ & 2624 & 2630 & 2651 \\
Avionics Hardware & $\mathrm{lb}$ & 467 & 467 & 467 \\
Empty Weight (EW) & $\mathrm{lb}$ & 13415 & 13974 & 14540 \\
Test Instrumentation Weight & $\mathrm{lb}$ & 200 & 500 & 500 \\
\hline
\end{tabular}

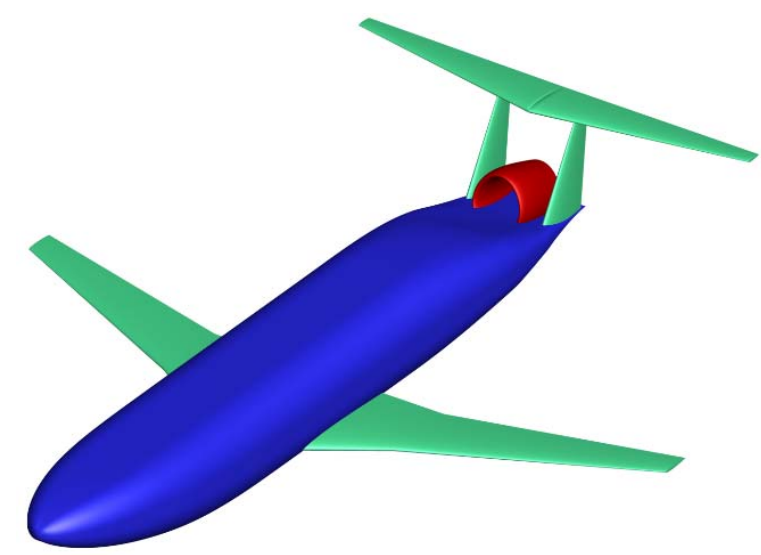

Figure 11. Single-engine ND8X variant as modeled in OpenVSP.

were all based on existing designs, with zero new design required. Further investigation revealed that each of these subsystems, even those based on salvaged hardware, would require some amount of new design. The new design factors applied to these subsystems ranged from $5 \%$ to $50 \%$.

A single engine variant of the ND8X using a CF34-3B1 engine was developed as an alternative to the twin engine nominal X-plane design. The motivation for this variant was the opportunity to further decrease the empty weight and reduce the number of engines required for the system, both impacting the system cost. Benefits other than cost include easier integration of the engine into the rear fuselage and vertical tail area, and a larger fan which is more reflective of the full scale vehicle. Using a single engine sacrifices the configuration commonality with the full scale vehicle, reduces the BLI operability research validity with the loss of the engine flow coupling, and a lack of redundancy in the propulsion system in case of engine failure. Ultimately, the impact on the research was not offset by the minor offset in cost and was not selected to move forward. The single-engine ND8X geometry is shown in Fig. 11.

The same varied inputs described in Table 5 were used in the single-engine ND8X to generate the weights data for the cost estimation data package. A comparison between most-like subsystem weights for the twinand single-engine variants is shown in Table 7 . Notice for the nominal design the empty weight is slightly over 13,000 pounds, nearly 1,000 pounds lighter than the twin-engine ND8X.

A summary of the twin-engine and single-engine ND8X designs is given in Table 8. The takeoff gross weight for the single engine variant was decreased from the twin-engine variant, but consumed more fuel. This was due to improved TSFC between the PW305B and the CF34-3B1 engines. The total cost with 50\% confidence was approximately $\$ 194$ million and $\$ 184$ million for the twin-engine and single-engine variants respectively, significantly less than the Iteration 1 total cost. The contractor cost to first flight cost is less still at $\$ 180$ and $\$ 167$ million. It was hoped that the contractor cost to first flight would be closer to $\$ 100$ million, but additional refinement of the cost estimation technique offset some of the more aggressive assumptions 
Table 7. Comparison of the twin- and single-engine ND8X most-likely subsystem weights.

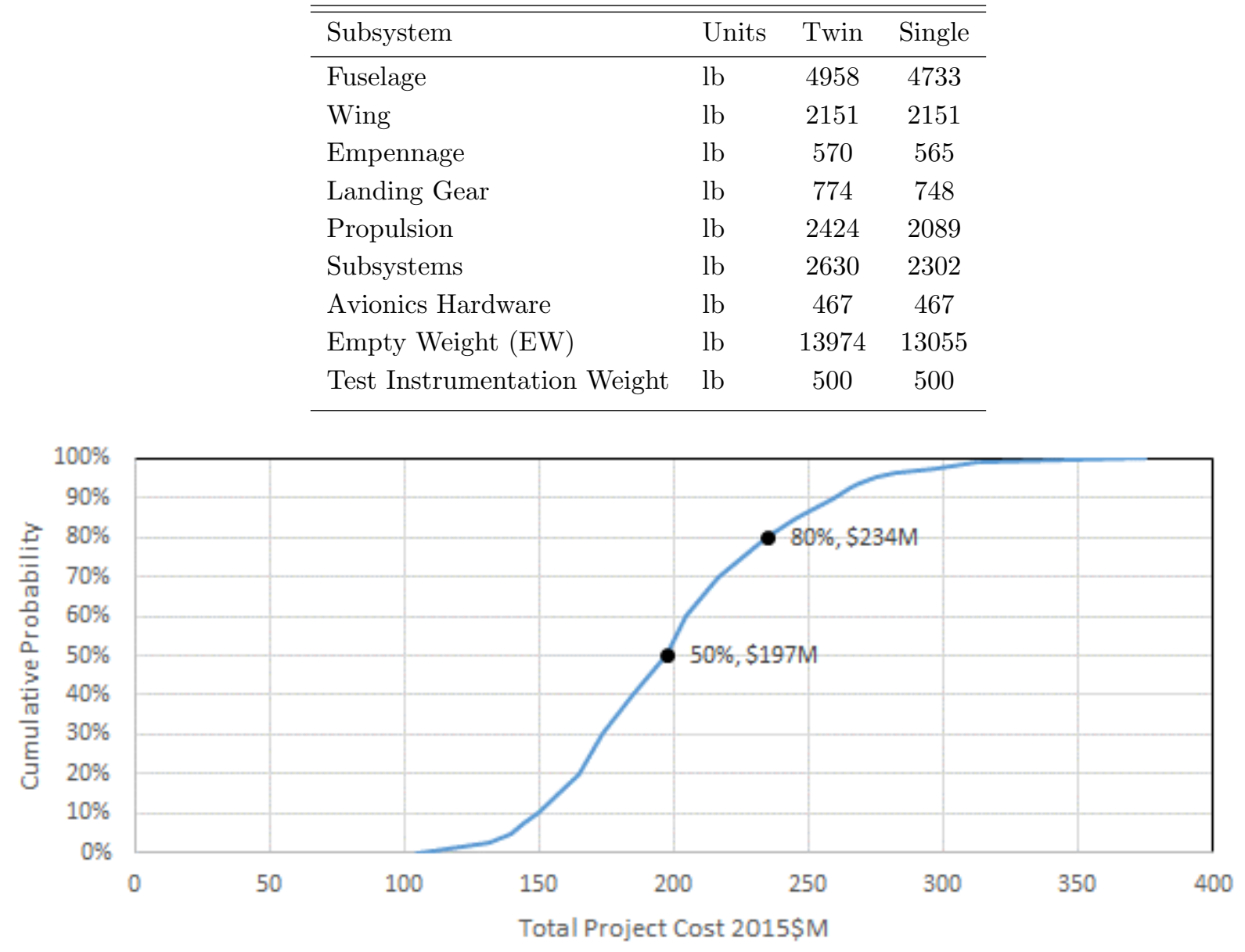

Figure 12. Cumulative probably distribution of total project cost for the twin-engine ND8X.

that were made in Iteration 2. A detailed breakout of cost estimate including the project management cost can be seen in Table 9, and a cumulative probability distribution of the total project cost is shown in Fig. 12 with markers shown for the $50 \%$ and $80 \%$ confidence level costs. It should also be noted that the final contractor cost to first flight fell very close to the initial estimate using the regression shown in Eq 1.

\section{Conclusions}

A conceptual model of a large scale configuration with a double-bubble fuselage with top-mounted boundary layer ingesting engines called the ND8X was designed. This design effort was part of a much larger study called the Convergent Aeronautic Solutions (CAS) X-plane study under the Transformative Aeronautics Concepts Program (TACP) at NASA. As part of this study, four configuration were modeled to develop a low-cost approach to design, build, and test a large scale X-plane where the contractor cost to first flight was less than $\$ 100$ million, of which the ND8X concept was one of the configurations. Achieving the research objectives of the X-plane was the major design driver while trying to find innovative low-cost solutions. Additional efforts in the CAS X-plane study include a broad range of trade studies to identify cost drivers, one of which was a trade of a manned versus unmanned concept. Through this particular trade study, it was determined that a manned system was more effective for a large scale ND8X.

Particular emphasis should be placed an establishing a set clear research objectives where flight test is the best or only way to achieve the research objectives. Excess research objectives will result in an increased set of requirements, requirements drive vehicle weight, and vehicle weight drives cost.

Two design iterations were performed on the ND8X. A vehicle scale of $70 \%$ was selected for the first 
Table 8. Summary of the ND8X twin- and single-engine designs at the end of Iteration 2 compared to Iteration 1 results.

\begin{tabular}{|c|c|c|c|c|}
\hline & \multirow[t]{2}{*}{ Units } & \multirow{2}{*}{$\begin{array}{l}\text { Iteration } 1 \\
\text { Powered }\end{array}$} & \multicolumn{2}{|c|}{ Iteration 2} \\
\hline & & & Single & Twin \\
\hline \multirow{3}{*}{$\begin{array}{r}\text { Contractor Cost to First Flight } \\
\text { Donor Aircraft } \\
\text { Scale }\end{array}$} & $\$ M$ & 394 & 167 & 180 \\
\hline & & Not Specified & Gulfstre & m G150 \\
\hline & $\%$ & 70 & $50 / 60$ & $50 / 60$ \\
\hline \multicolumn{5}{|l|}{ Mission Parameters } \\
\hline TOGW & $\mathrm{lb}$ & 33,300 & 21,000 & 21,800 \\
\hline OEW & $\mathrm{lb}$ & 20,300 & 13,000 & 14,000 \\
\hline Payload & $\mathrm{lb}$ & 500 & 500 & 500 \\
\hline Total Fuel & $\mathrm{lb}$ & 11,800 & 6800 & 6600 \\
\hline Endurance & $\mathrm{hr}$ & 4 & & 3 \\
\hline \multicolumn{5}{|l|}{ Aircraft Parameters } \\
\hline \multicolumn{2}{|l|}{$\mathrm{AR}$} & 19.6 & & 8.8 \\
\hline Wing Area & $\mathrm{ft}^{2}$ & 580 & & 350 \\
\hline Wing Span & $\mathrm{ft}$ & 88 & & 56 \\
\hline Wing Sweep & $\operatorname{deg}$ & 5.6 & & 23.3 \\
\hline Wing Loading & $\mathrm{lb} / \mathrm{ft}^{2}$ & 58 & 60 & 62 \\
\hline Design Mach & & 0.72 & & 0.8 \\
\hline Design Altitude & $\mathrm{ft}$ & 24,500 & & 22,200 \\
\hline Design $C_{L}$ & & 0.2 & 0.15 & 0.15 \\
\hline Thrust per Engine & $\mathrm{lb}$ & 5700 & 8700 & 5200 \\
\hline
\end{tabular}


Table 9. Detailed costs breakdown for the Iteration 2 twin- and single-engine ND8X at the 0.5 probability in FY2015\$K.

\begin{tabular}{ccccc}
\hline \hline & \multicolumn{2}{c}{ Contractor Cost to First Flight } & \multicolumn{2}{c}{ Total Project Cost } \\
& 2 Engines & 1 Engine & 2 Engines & 1 Engine \\
\hline X-Plane Project & 180,475 & 167,637 & 197,158 & 184,311 \\
Project Management & 7,274 & 6,757 & 7,408 & 6,891 \\
Project Analysis & - & - & 8,757 & 8,757 \\
Advanced Concepts & - & - & 887 & 887 \\
Technology Development & 173,201 & 160,880 & 173,201 & 160,880 \\
Air Vehicle & 171,711 & 159,391 & 171,711 & 159,391 \\
Vehicle Integration & 18,727 & 17,519 & 18,727 & 17,519 \\
Donor Aircraft & 16,146 & 12,468 & 16,146 & 12,468 \\
Airframe & 75,336 & 73,017 & 75,336 & 73,017 \\
Fuselage & 51,929 & 49,684 & 51,929 & 49,684 \\
Wing & 4,360 & 4,373 & 4,360 & 4,373 \\
Empennage & 18,455 & 18,385 & 18,455 & 18,385 \\
Landing Gear & 592 & 575 & 592 & 575 \\
Propulsion & 24,218 & 21,406 & 24,218 & 21,406 \\
Subsystems & 31,680 & 29,353 & 31,680 & 29,353 \\
Avionics Hardware & 1,901 & 1,906 & 1,901 & 1,906 \\
Software & 3,703 & 3,722 & 3,703 & 3,722 \\
Test Instrumentation & 1,489 & 1,489 & 1,489 & 1,489 \\
Validation \& Test & - & - & 6,905 & 6,896 \\
\hline
\end{tabular}

iteration resulting in a vehicle contractor cost to first flight of $\$ 394 \mathrm{M}$. As expected, the cost far exceeded the goal of $\$ 100 \mathrm{M}$. The Iteration 1 design was then used to identify the major cost drivers that could then be used in the Iteration 2 ND8X design. The Iteration 2 design was scaled down to a selected target empty weight and made extensive use of salvaged parts including a wing from a Gulfstream G150 business jet. This resulted in a fuselage and empennage that was at $60 \%$ scale and a wing that was at $50 \%$ scale. A single engine variant of the ND8X was explored as a potential lower cost savings, but resulted in vehicle with reduced research value. As such, the twin-engine variant of the ND8X was preferred and had a contractor cost to first flight of $\$ 180 \mathrm{M}$. The Iteration $2 \mathrm{ND} 8 \mathrm{X}$ cost was significantly reduced from the Iteration 1 design, but fell short of the study goal. There is still opportunity for reduced vehicle cost by reducing the fuselage and empennage scale from $60 \%$ and this could be explored in future studies.

\section{Acknowledgments}

The authors would like to thank Craig Nickol of the NASA Langley Research Center for coordinating the design team leads as part of the CAS X-Plane study while providing design decision support, Shishir Pandya of the NASA Ames Research Center for generating a stereolithography (STL) file from the CFD mesh of the D8 wind tunnel model, and Rob McDonald for generating the OpenVSP fuselage component from the STL file using OpenVSP's Fit Model. This work was funded under the Convergent Aeronautics Solutions project, under the Transformative Aeronautics Concepts Program at NASA.

\section{References}

1 "NASA Aeronautics Strategic Implementation Plan," 2014.

${ }^{2}$ Drela, M., "Development of the D8 Transport Configuration," 29th AIAA Applied Aerodynamics Conference, American Institute of Aeronautics and Astronautics, Honolulu, HA, June 2011, pp. 1-14, AIAA- 
2011-3970.

${ }^{3}$ Uranga, A., Drela, M., Greitzer, E. M., Titchener, N. A., Lieu, M. K., Siu, N. M., and Huang, A. C., "Preliminary Experimental Assessment of the Boundary Layer Ingesting Benefit for the D8 Aircraft," 52nd Aerospace Sciences Meeting, American Institute of Aeronautics and Astronautics, National Harbor, MD, January 2014, pp. 1-25, AIAA-2014-0906.

${ }^{4}$ Pandya, S. A., Huang, A., Espitia, A., and Uranga, A., "Computational Assessment of the Boundary Layer Ingesting Nacelle Design of the D8 Aircraft," 52nd Aerospace Sciences Meeting, American Institute of Aeronautics and Astronautics, National Harbor, MD, January 2014, pp. 1-14, AIAA-2014-0907.

${ }^{5}$ Pandya, S. A., "External Aerodynamics Simulations for the MIT D8 "Double-Bubble" Aircraft Design," Seventh International Conference on Computational Fluid Dynamics, Big Island, HA, July 2012, pp. 1-16, ICCFD7-4304.

${ }^{6}$ Greitzer, E. M., et al., "N+3 Aircraft Concept Designs and Trade Studies, Final Report," Contractor Report Volume I, National Aeronautics and Space Administration, 2010, NASA/CR-2010-216794.

${ }^{7}$ Greitzer, E. M., et al., "N+3 Aircraft Concept Designs and Trade Studies, Final Report," Contractor Report Volume II, National Aeronautics and Space Administration, 2010, NASA/CR-2010-216794.

${ }^{8}$ Hahn, A. S., "Vehicle Sketch Pad: A Parametric Geometry Modeler for Conceptual Aircraft Design," 48th AIAA Aerospace Sciences Meeting, American Insittue of Aeronautics and Astronautics, Orlando, FL, 2010, pp. 1 - 11, AIAA-2010-0657.

${ }^{9}$ Hahn, A. S., "Vehicle Sketch Pad Aircraft Modeling Strategies," 61st AIAA Aerospace Sciences Meeting, American Insittue of Aeronautics and Astronautics, Grapevine, TX, 2013, pp. 1 - 9, AIAA-2013-0331.

${ }^{10}$ Fredericks, W. J., Antcliff, K. R., Costa, G., Deshpande, N., Moore, M. D., San Miguel, E. A., and Snyder, A. N., "Aircraft Conceptual Design Using Vehicle Sketch Pad," 48th AIAA Aerospace Sciences Meeting, American Institute of Aeronautics and Astronautics, Orlando, FL, January 2010, pp. 1-17, AIAA-20100658.

${ }^{11}$ Belben, J. B. and McDonald, R. A., "Enabling Rapid Conceptual Design Using Geometry-Based MultiFidelity Models In VSP," 51st AIAA Aerospace Sciences Meeting, American Institue of Aeronautics and Astronautics, Grapevine, TX, January 2013, pp. 1-13, AIAA-2013-0328.

12 Olson, E. D., "Three-Dimensional Modeling of Aircraft High-Lift Components with Vehicle Sketch Pad," 54th AIAA Aerospace Sciences Meeting, American Institute of Aeronautics and Astronautics, San Diego, CA, January 2016, pp. 1-14, AIAA-2016-1274.

${ }^{13}$ Waddington, M. J. and McDonald, R. A., "Development of an Interactive Wave Drag Capability for the OpenVSP Parametric Geometry Tool," 15th AIAA Aviation Technology, Integration, and Operations Conference, American Institute of Aeronautics and Astronautics, Dallas, TX, June 2015, pp. 1-11, AIAA2015-2548.

${ }^{14}$ Gary, A. M. and McDonald, R. A., "Parametric Identification of Surface Regions in OpenVSP for Improved Engineering Analysis," 53rd AIAA Aerospace Sciences Meeting, American Institute of Aeronautics and Astronautics, Kissimmee, FL, January 2015, pp. 1-13, AIAA-2015-1016.

15 McDonald, R. A., "Interactive Reconstruction of 3D Models in the OpenVSP Parametric Geometry Tool," 53rd AIAA Aerospace Sciences Meeting, American Institute of Aeronautics and Astronautics, Kissimmee, FL, January 2015, pp. 1-10, AIAA-2015-1014.

${ }^{16}$ Gloudemans, J. R. and McDonald, R. A., "User Defined Components in the OpenVSP Parametric Geometry Tool," 15th AIAA Aviation Technology, Integration, and Operations Conference, American Institute of Aeronautics and Astronautics, Dallas, TX, June 2015, pp. 1-7, AIAA-2015-2547.

${ }^{17}$ McCullers, L., "Aircraft Configuration Optimization Including Optimized Flight Profiles," Proceedings of the Symposium on Recent Experiences in Multidisciplinary Analysis and Optimization, No. NASA CP2327, 1984, pp. 395-412. 
${ }^{18}$ Lytle, J., "The Numerical Propulsion System Simulation: An Overview," Technical Memo NASA TM2000-209915, NASA, 2000.

${ }^{19}$ NPSS Consortium, NPSS User Guide Software Release: 2.3.0, The Ohio Aerospace Institute, Cleveland, $\mathrm{OH}, 2010$.

${ }^{20}$ NPSS Consortium and NASA Glenn Research Center, NPSS Reference Sheets Software Release: NPSS 1.6.5, NASA, Cleveland, OH, 2008.

${ }^{21}$ Elliott, R. D., "Empirical Drag Estimation Technique (EDET) User's Manual," Company Report LR 28788, Lockheed-California, December 1978.

${ }^{22}$ Feagin, R. C. and Morrison, W. D., "Delta Method, An Empirical Drag Buildup Technique," Contractor Report NASA/CR-151971, Lockheed-California Co., Burbank, CA, December 1978.

${ }^{23}$ Bradley, K. R., "A Sizing Methodology for the Conceptual Design of Blended-Wing-Body Transports," Contractor Report NASA/CR-2004-213016, NASA Langley Research Center, Hampton, VA, 2004.

${ }^{24}$ Welstead, J., Conceptual Design Optimization of an Augmented Stability Aircraft Incorporating Dynamic Response Performance Constraints, Ph.D. thesis, Auburn University, 2014.

${ }^{25}$ Wells, D. P., Horvath, B. L., and McCullers, L. A., "The Flight Optimization System Preliminary Weights Estimation Method," Technical Memo NASA TM-2016-XXXXXX, NASA Langley Research Center, Hampton, VA, 2016, (submitted for publication).

${ }^{26}$ Raymer, D. P., Aircraft Design: A Conceptual Approach, 3rd ed., American Institute of Aeronautics and Astronautics, Reston, VA, 2006.

${ }^{27}$ Lechniak, J. A. and Melton, J. E., "Manned vs. Unmanned Considerations for Future X-planes," Aviation and Aeronautics Forum and Exposition, American Insitute of Aeronautics and Astronautics, Denver, CO, June 2017, (submitted for publication). 